\title{
Research on the Supernetwork Equalization Model of Multilayer Attributive Regional Logistics Integration
}

\author{
Jian Xu, Yanna Yin, Xin Wen (D), and Guozhi Lin \\ School of Management, Shenyang University of Technology, Shenyang 110870, China \\ Correspondence should be addressed to Xin Wen; wenxin@sut.edu.cn
}

Received 12 June 2019; Accepted 9 August 2019; Published 24 November 2019

Academic Editor: Paolo Renna

Copyright (C) 2019 Jian Xu et al. This is an open access article distributed under the Creative Commons Attribution License, which permits unrestricted use, distribution, and reproduction in any medium, provided the original work is properly cited.

\begin{abstract}
Based on the multi-level structure attributes of regional logistics, regional logistics integration presents complex features. Therefore, according to the operational requirements of regional logistics integration, we built a regional logistics network structure model consisting of infrastructure, information resources, and organizational networks; selected the level of relationship between different layers and information dissemination, and transport flow as decision variables. We built a supernetwork mathematical model of regional logistics integration with multiple layers of attributes. Considering the constraints of marginal cost changes and overall revenue, we found an equilibrium solution for the operation of regional logistics integration supernetwork. That is, the optimal match between the level of relationship, the level of information dissemination and the transportation flow, provides a reference basis for the formulation of relevant policies and implementation strategies.
\end{abstract}

\section{Introduction}

Coordination, cooperation and frequent trade exchanges among different regions reflect the importance of cooperation among regions. Interregional logistics links and collaboration directly affect the cost and efficiency of interregional trade flows. Therefore, the planning and construction of logistics network system formed by interregional logistics interconnection and cooperation has become an important issue of recent concern. For the planning and construction of regional logistics network system, we need to deal with many practical problems, such as logistics facilities and node layout, logistics transportation cost optimization, logistics service efficiency and service quality. These have further affected the rapid, healthy and coordinated development of the regional economy. Therefore, the logistics system of each node in the regional logistics network system should be standardized and coordinated, which is not only an important basis to ensure the effective connection of logistics between different regions, but also an important prerequisite to determine the efficiency and service quality of the whole region and parts of the logistics.

The research and practice of regional logistics integration are broadly divided into two fields: planning design and structural optimization. The former is mainly from the perspective of regional economic development, which puts forward the planning and designing direction and policy of regional logistics integration; the latter is from the development of regional logistics itself, studies the key factors, evolution mechanism and ability evaluation that affect regional logistics development. Among them, the research on the structure design and optimization of regional logistics network is gradually becoming one of the hot topics in theory and practice. In this field, there are three main directions: (1) Research on the construction of regional logistics network and its influencing factors. For example, based on the perspective of optimal cost and value risk, domestic and foreign scholars put forward the design method of spoke structure network, as well as the delivery routes and scheduling of hub nodes [1-4]; or take a certain area as an actual case to study the positioning of logistics center in logistics transportation network [5-7]; or study the impact of system and policy on the construction of logistics network in coastal cities under similar conditions of natural environment and other characteristics [8-10]. (2) Research on the construction and optimization of regional logistics network. The existing achievements are based on the theories and methods of complex network, social network, and dynamic evolution, combined with specific research objects, put forward the structure model and optimization countermeasures of regional 
logistics network [11-15]. Specifically, design and construct of the structural model of regional logistics integration can effectively provide a basis for the theory and practice in the field of regional logistics. Therefore, on the basis of defining the structure relationship of regional logistics integration, this paper gives the graphical model and mathematical model of regional logistics integration structure by applying the theory and method of supernetwork. Through model solving and simulation, we put forward the optimization and management strategy of supernetwork equilibrium model of regional logistics integration, which can provide technical support for optimizing regional logistics structure and guiding regional logistics integration operation in practice.

\section{Analysis on the Properties of Regional Logistics Integration Supernetwork with Hierarchical Structure}

As regional logistics integration involves all kinds of logistics activities inside and outside the region, as well as various resources supporting logistics activities, it is essentially an organic system composed of infrastructure, information resources and organizational networks. Therefore, regional logistics integration has the characteristics of supernetwork, and can build its supernetwork structure model, as shown in Figure 1 and Figure 2.

Based on Figure 1 and Figure 2, regional logistics integration has supernetwork characteristics such as multiagent, multilevel, multiattribute, multicriteria etc., as shown in Table 1.

\section{Supernetwork Equilibrium Model and Solution Analysis of Regional Logistics Integration}

3.1. Basic Hypothesis. Suppose there are $K$ individuals in the logistics system supernetwork $S$. One of them exists in three sub-systems of regional logistics integration and has corresponding relationship. In the sub-system of regional logistics, it is called node. $i, j$ are the two nodes in the subsystem. According to the analysis of the relationship between the connotation of logistics system and its structure, the mathematical models are as follows.

(1) $h_{i j}$ is the level of relationship between nodes $i, j$ in the organization operation network, which indicates the degree of close connection, mutual trust, and communication. The value of $h_{i j}$ ranges from 0 to 1 , and the cost of establishing a relationship level $h_{i j}$ is $C_{i j}=C_{i j}\left(h_{i j}\right)$, earnings are $E_{i j}$, and $E_{i j}=E_{i j}\left(h_{i j}\right)$, establishing a relationship level $h_{i j}$ has certain risks $R_{i j}$, and $R_{i j}=R_{i j}\left(h_{i j}\right)$.

(2) In logistics information and standardization network, $q_{i j}$ represents information dissemination among nodes. $q_{i j}$ is a comprehensive index of the amount of information dissemination, the convenience of communication channels and the degree of

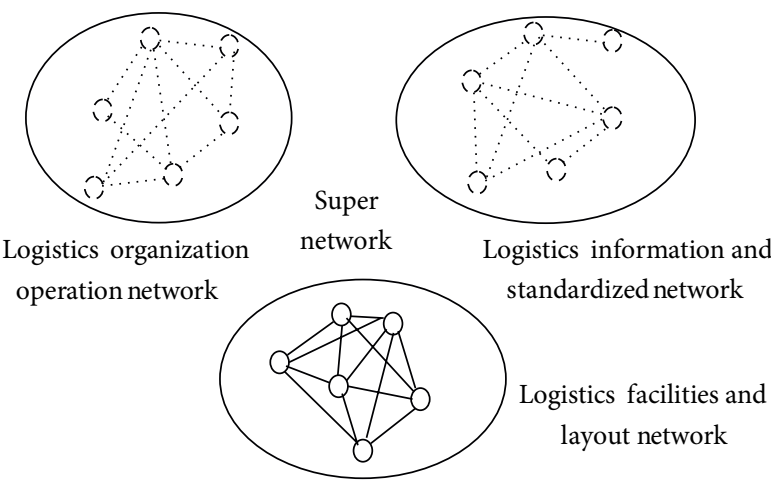

.... Relational level

- - - Information dissemination

— Transport flow

FIgURE 1: Supernetwork structure model of regional logistics integration.

standardization, its value range is between 0 and 1 , establishing a corresponding level of $q_{i j}$ requires a cost of $B_{i j}$, and $B_{i j}=B_{i j}\left(q_{i j}, h_{i j}\right)$, for establishing each information transmission $q_{i j}$, the earning is $u_{i j}$, and $u_{i j}=u_{i j}\left(q_{i j}\right)$, that is the earning function of $q_{i j}$.

(3) In the logistics facilities and layout network, $p_{i j}$ represent the transport flow between nodes. Transportation flow is a comprehensive reflection of the transport distance, the degree of transport convenience and the number of transshipments between the two nodes. The larger the transport flow, the lower the unit cost of transport between nodes, the more convenient the transport is, and the value range of transport flow $p_{i j}$ is between 0 and 1. For establishing a transport flow connection $p_{i j}$ required cost $A_{i j}$, and $A_{i j}=A_{i j}\left(p_{i j}, q_{i j}\right)$, for establishing a transport flow can obtained the corresponding benefit $V_{i j}$, and $V_{i j}=V_{i j}\left(p_{i j}\right)$.

In this paper, $h_{i j} q_{i j}$, and $p_{i j}$ are the decision variables of the model, which correspond to the three edges of the supernetwork model of regional logistics integration structure. They are comprehensive indicators, which need to be quantified here. Based on the relevant research, this paper constructs three quantitative indicators, as shown in Table 2.

All the above functions' constructions are based on the previous research on the composition of logistics system and its interaction. For example, the cost of freight transport flow is affected by the size of transport flow $p_{i j}$, and considering the impact of information on logistics transport, this paper considers that the cost of transport flow is a function of transport flow $p_{i j}$ and information flow $q_{i j^{\circ}}$ Similarly, the sharing and transmission of logistics information will be affected by the level of inter-organizational relations, so the cost of logistics information is a function of information dissemination $q_{i j}$ and organizational relationship level $h_{i i}$. At the same time, the establishment of network flow will bring certain benefits, which will form the benefit function of different network systems. In order to facilitate the study, this paper assumes that the above functions are continuous. 


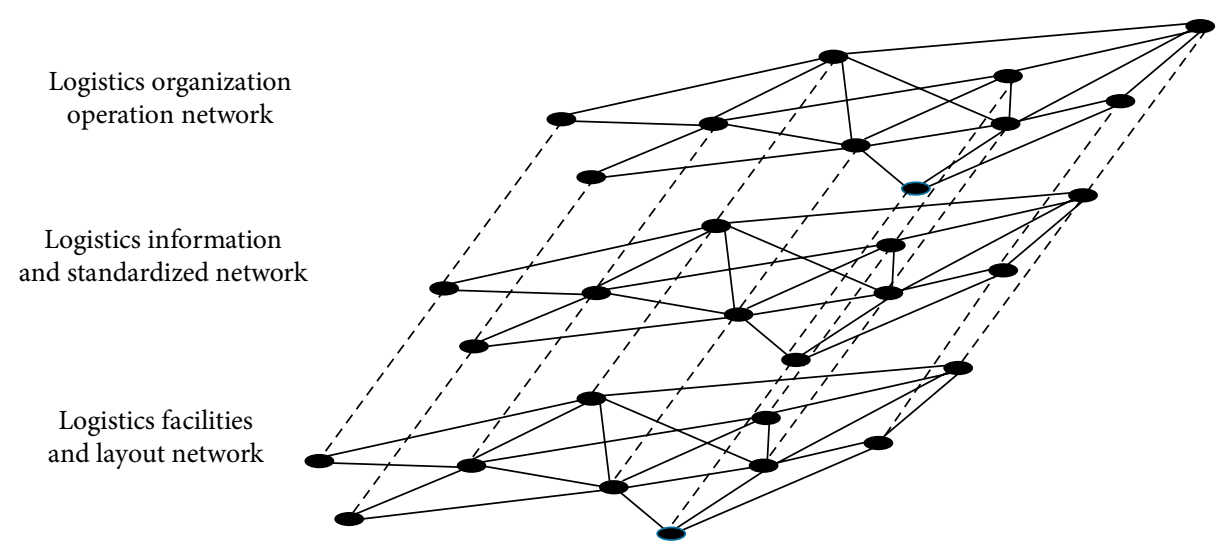

FIGURE 2: The three-dimensional hierarchical relationship of regional logistics integration network.

TABLE 1: Supernetwork characteristics of regional logistics integration.

\begin{tabular}{lcc}
\hline No. & Characteristic name & Specific instructions \\
1 & Multi-agent & The main bodies involved in regional logistics integration include government departments, logistics \\
enterprises, trade associations and users.
\end{tabular}

TABLE 2: Evaluation index of decision variables.

\begin{tabular}{|c|c|c|c|}
\hline Meaning & Level 1 index & Level 2 index & Level 3 index \\
\hline \multirow{3}{*}{$\begin{array}{l}\text { Level of relationship } \\
\text { between } i \text { and } j\end{array}$} & & Level of organizational management & \\
\hline & $h_{i j}$ & Collaboration and mutual trust mechanism & \\
\hline & & Level of partner & \\
\hline \multirow{3}{*}{$\begin{array}{l}\text { Logistics information } \\
\text { dissemination between } i \\
\text { and } j\end{array}$} & \multirow{3}{*}{$q_{i j}$} & Information infrastructure equipment & \\
\hline & & Information exchange and sharing mechanism & \\
\hline & & Information dissemination & \\
\hline \multirow{2}{*}{$\begin{array}{l}\text { Transportation flows } \\
\text { between } i \text { and } j\end{array}$} & \multirow{2}{*}{$p_{i j}$} & $\begin{array}{l}\text { Logistics infrastructure and equipment } \\
\text { technology level }\end{array}$ & \\
\hline & & Traffic distance and transportation accessibility & $\begin{array}{c}\text { Distance of different modes of transport } \\
\text { Transportation time and cost }\end{array}$ \\
\hline
\end{tabular}

The goal of an individual in supernetwork is to maximize the value of the relationship level, maximize the information benefit, maximize the transportation benefit, minimize the risk and minimize the cost, which are formulas (1)-(5) respectively.

$$
\begin{gathered}
\max \sum_{j=1}^{k} E_{i j}=\max \sum_{j=1}^{k} E_{i j}\left(h_{i j}\right), \\
\max \sum_{j=1}^{k} U_{i j}=\max \sum_{j=1}^{k} U_{i j}\left(q_{i j}\right), \\
\max \sum_{j=1}^{k} V_{i j}=\max \sum_{j=1}^{k} V_{i j}\left(p_{i j}\right), \\
\min \sum_{j=1}^{k} R_{i j}=\min \sum_{j=1}^{k} R_{i j}\left(h_{i j}\right), \\
\min \left(\sum_{j=1}^{k} C_{i j}\left(h_{i j}\right)+\sum_{j=1}^{k} B_{i j}\left(q_{i j}, h_{i j}\right)+\sum_{j=1}^{k} A_{i j}\left(p_{i j}, q_{i j}\right)\right) .
\end{gathered}
$$

Let the weights of the above five objectives are $\alpha_{1}, \alpha_{2}, \alpha_{3}$, $\alpha_{4}, \alpha_{5}$, and $\alpha_{1}+\alpha_{2}+\alpha_{3}+\alpha_{4}+\alpha_{5}=1$. Therefore, the objective function of the individual is shown in model (6).

$$
\begin{aligned}
\max & \alpha_{1} \sum_{j=1}^{k} E_{i j}\left(h_{i j}\right)+\alpha_{2} \sum_{j=1}^{k} U_{i j}\left(q_{i j}\right)+\alpha_{3} \sum_{j=1}^{k} V_{i j}\left(p_{i j}\right)-\alpha_{4} \sum_{j=1}^{k} R_{i j}\left(h_{i j}\right) ; \\
& -\alpha_{5}\left(\sum_{j=1}^{k} C_{i j}\left(h_{i j}\right)+\sum_{j=1}^{k} B_{i j}\left(q_{i j}, h_{i j}\right)+\sum_{j=1}^{k} A_{i j}\left(p_{i j}, q_{i j}\right)\right), \\
& s t\left\{\begin{array}{l}
0 \leq h_{i j} \leq 1, \\
0 \leq q_{i j} \leq 1 ; i, j=1,2 \ldots k \ldots K . \\
0 \leq p_{i j} \leq 1
\end{array}\right.
\end{aligned}
$$

From the analysis of variational inequalities and supernetwork theory, we can see that the optimal solution satisfying the above formulation and the following variational inequalities are valid at the same time, it is shown in formula (7). 


$$
\begin{gathered}
{\left[\alpha_{5}\left(\sum_{i=1}^{k} \sum_{j=1}^{k} \frac{\partial C_{i j}\left(h_{i j}{ }^{*}\right)}{\partial h_{i j}}+\sum_{i=1}^{k} \sum_{j=1}^{k} \frac{\partial B_{i j}\left(q_{i j}{ }^{*}, h_{i j}{ }^{*}\right)}{\partial h_{i j}}\right)+\alpha_{4} \sum_{i=1}^{k} \sum_{j=1}^{k} \frac{\partial R_{i j}\left(h_{i j}{ }^{*}\right)}{\partial h_{i j}}-\alpha_{1} \sum_{i=1}^{k} \sum_{j=1}^{k} \frac{\partial E_{i j}\left(h_{i j}{ }^{*}\right)}{\partial h_{i j}}\right]} \\
\left(h_{i j}-h_{i j}{ }^{*}\right)+\left[\alpha_{5}\left(\sum_{i=1}^{k} \sum_{j=1}^{k} \frac{\partial B_{i j}\left(q_{i j}{ }^{*}, h_{i j}{ }^{*}\right)}{\partial q_{i j}}+\sum_{i=1}^{k} \sum_{j=1}^{k} \frac{\partial A_{i j}\left(p_{i j}{ }^{*}, q_{i j}{ }^{*}\right)}{\partial q_{i j}}\right)-\alpha_{3} \sum_{i=1}^{k} \sum_{j=1}^{k} \frac{\partial U_{i j}\left(q_{i j}{ }^{*}\right)}{\partial q_{i j}}\right] \\
\left(q_{i j}-q_{i j}^{*}\right)+\left(\alpha_{5} \sum_{i=1}^{k} \sum_{j=1}^{k} \frac{\partial A_{i j}\left(p_{i j}^{*}, q_{i j}{ }^{*}\right)}{\partial p_{i j}}-\alpha_{3} \sum_{i=1}^{k} \sum_{j=1}^{k} \frac{\partial V_{i j}\left(p_{i j}{ }^{*}\right)}{\partial p_{i j}}\right)\left(p_{i j}-p_{i j}{ }^{*}\right) \geq 0 .
\end{gathered}
$$

For the convenience of studying hypotheses, as shown in formula (8)-(10).

$$
\begin{aligned}
F_{1}\left(X^{*}\right)= & \alpha_{5}\left(\sum_{i=1}^{k} \sum_{j=1}^{k} \frac{\partial C_{i j}\left(h_{i j}{ }^{*}\right)}{\partial h_{i j}}+\sum_{i=1}^{k} \sum_{j=1}^{k} \frac{\partial B_{i j}\left(q_{i j}{ }^{*}, h_{i j}{ }^{*}\right)}{\partial h_{i j}}\right) \\
& +\alpha_{4} \sum_{i=1}^{k} \sum_{j=1}^{k} \frac{\partial R_{i j}\left(h_{i j}{ }^{*}\right)}{\partial h_{i j}}-\alpha_{1} \sum_{i=1}^{k} \sum_{j=1}^{k} \frac{\partial E_{i j}\left(h_{i j}{ }^{*}\right)}{\partial h_{i j}} . \\
F_{2}\left(X^{*}\right)= & \alpha_{5}\left(\sum_{i=1}^{k} \sum_{j=1}^{k} \frac{\partial B_{i j}\left(q_{i j}{ }^{*}, h_{i j}{ }^{*}\right)}{\partial q_{i j}}+\sum_{i=1}^{k} \sum_{j=1}^{k} \frac{\partial A_{i j}\left(p_{i j}{ }^{*}, q_{i j}{ }^{*}\right)}{\partial q_{i j}}\right) \\
& -\alpha_{3} \sum_{i=1}^{k} \sum_{j=1}^{k} \frac{\partial U_{i j}\left(q_{i j}{ }^{*}\right)}{\partial q_{i j}},{ }^{k} \\
F_{3}\left(X^{*}\right)= & \alpha_{5} \sum_{i=1}^{k} \sum_{j=1}^{k} \frac{\partial A_{i j}\left(p_{i j}^{*}, q_{i j}{ }^{*}\right)}{\partial p_{i j}}-\alpha_{3} \sum_{i=1}^{k} \sum_{j=1}^{k} \frac{\partial V_{i j}\left(p_{i j}{ }^{*}\right)}{\partial p_{i j}} .
\end{aligned}
$$

The above variational inequalities can be expressed in the standard form: $\left\langle F\left(x^{*}\right), x-x^{*}\right\rangle \geq 0$, among, $F\left(X^{*}\right)=\left(F_{1}\left(X^{*}\right)\right.$, $\left.F_{2}\left(X^{*}\right), F_{3}\left(X^{*}\right)\right), X=\left(h_{i j}, q_{i j}, p_{i j}\right), X^{*}=\left(h_{i j}{ }^{*}, q_{i j}{ }^{*}, p_{i j}{ }^{*}\right)$.

Through the above, the concept and model of logistics architecture supernetwork are transformed into a mathematical model of variational inequality, which is convenient for analysis and solution.

3.2. Model Analysis and Solution. There are many methods for solving variational inequalities, including continuous algorithm, (quasi-)Newton algorithm, general iteration model, projection algorithm, projection contraction algorithm and so on. This article does not make a specific introduction, the interested readers can refer to the relevant literature. This section focuses on the economic significance of variational inequalities, while in the follow-up simulation model, the model is mainly solved from a mathematical point of view.

From the perspective of economics, the first left part of the variational inequality (7) can be viewed as the marginal total cost of the relationship level in the operation of regional logistics system, as shown in formula (11). And the reason is that these are functions of $h_{i j}$ in relation to each other. Accordingly, formula (12) represents the marginal cost of the relationship level $h_{i j}$ in the organizational operation network, formula (13) represents the marginal cost of the relationship level $h_{i j}$ in the information network, formula (14) represents the marginal risk cost of the relationship level $h_{i j}$ in the organizational operation network, and formula (15) represents the marginal benefit of the relationship level $h_{i j}$ in the organizational operation network.

$$
\begin{gathered}
\sum_{i=1}^{k} \sum_{j=1}^{k} \frac{\partial C_{i j}\left(h_{i j}{ }^{*}\right)}{\partial h_{i j}}+\sum_{i=1}^{k} \sum_{j=1}^{k} \frac{\partial B_{i j}\left(q_{i j}{ }^{*}, h_{i j}{ }^{*}\right)}{\partial h_{i j}} \\
+\sum_{i=1}^{k} \sum_{j=1}^{k} \frac{\partial R_{i j}\left(h_{i j}{ }^{*}\right)}{\partial h_{i j}}, \\
\sum_{i=1}^{k} \sum_{j=1}^{k} \frac{\partial C_{i j}\left(h_{i j}{ }^{*}\right)}{\partial h_{i j}}, \\
\sum_{i=1}^{k} \sum_{j=1}^{k} \frac{\partial B_{i j}\left(q_{i j}{ }^{*}, h_{i j}{ }^{*}\right)}{\partial h_{i j}}, \\
\sum_{i=1}^{k} \sum_{j=1}^{k} \frac{\partial R_{i j}\left(h_{i j}{ }^{*}\right)}{\partial h_{i j}}, \\
\sum_{j=1}^{k} \frac{\partial E_{i j}\left(h_{i j}{ }^{*}\right)}{\partial h_{i j}} .
\end{gathered}
$$

Only when the total marginal cost of the relationship level multiplies the corresponding weight equal to the marginal income of the relationship level multiplied by the corresponding weight, the relationship horizontal flow $h_{i j}{ }^{*}$ in the organizational operation network is balanced, and the individual is more willing to maintain this stable relationship level, this relationship level is conducive to the operation of the logistics system, and can play the best role of the logistics system.

Part 2 of the variational inequality shows that, when the total marginal cost of information dissemination in the information and standardized network, which is formula (16) multiplied by the corresponding weight equal to the marginal benefit formula (17), that is formula (18) is established, the information flow in the logistics system supernetwork reaches equilibrium. This state is conducive to the interactive dissemination of information. The dissemination of information among the main bodies in the regional logistics integration is the most efficient and brings the best marginal benefits. At this time, information and standardization can provide the most necessary guarantee for the operation of the logistics system.

$$
\begin{gathered}
\sum_{i=1}^{k} \sum_{j=1}^{k} \frac{\partial B_{i j}\left(q_{i j}{ }^{*}, h_{i j}{ }^{*}\right)}{\partial q_{i j}}+\sum_{i=1}^{k} \sum_{j=1}^{k} \frac{\partial A_{i j}\left(p_{i j}{ }^{*}, q_{i j}{ }^{*}\right)}{\partial q_{i j}}, \\
\sum_{i=1}^{k} \sum_{j=1}^{k} \frac{\partial U_{i j}\left(q_{i j}{ }^{*}\right)}{\partial q_{i j}},
\end{gathered}
$$




$$
\begin{aligned}
& \alpha_{5}\left(\sum_{i=1}^{k} \sum_{j=1}^{k} \frac{\partial B_{i j}\left(q_{i j}{ }^{*}, h_{i j}{ }^{*}\right)}{\partial q_{i j}}+\sum_{i=1}^{k} \sum_{j=1}^{k} \frac{\partial A_{i j}\left(p_{i j}{ }^{*}, q_{i j}{ }^{*}\right)}{\partial q_{i j}}\right) \\
& =\alpha_{3} \sum_{i=1}^{k} \sum_{j=1}^{k} \frac{\partial U_{i j}\left(q_{i j}{ }^{*}\right)}{\partial q_{i j}} .
\end{aligned}
$$

Similarly, when the marginal cost formula (19) multiplied by the corresponding weight is equal to the marginal benefit formula (20) multiplied by the corresponding weight, that is, when formula (21) is established, the transport flow reaches equilibrium, otherwise maintaining the transport flow is nonprofit, which requires a certain cost.

$$
\begin{gathered}
\sum_{i=1}^{k} \sum_{j=1}^{k} \frac{\partial A_{i j}\left(p_{i j}, q_{i j}{ }^{*}\right)}{\partial p_{i j}}, \\
\sum_{i=1}^{k} \sum_{j=1}^{k} \frac{\partial V_{i j}\left(p_{i j}{ }^{*}\right)}{\partial p_{i j}}, \\
\alpha_{5} \sum_{i=1}^{k} \sum_{j=1}^{k} \frac{\partial A_{i j}\left(p_{i j}^{*}, q_{i j}{ }^{*}\right)}{\partial p_{i j}}=\alpha_{3} \sum_{i=1}^{k} \sum_{j=1}^{k} \frac{\partial V_{i j}\left(p_{i j}{ }^{*}\right)}{\partial p_{i j}} .
\end{gathered}
$$

With the help of variational inequality theory, through the analysis of the model, we can find out the integration of regional logistics and give some guidance to economic management from the theoretical point of view. The optimal value of all kinds of investment in logistics system needs to be determined from the perspective of marginal revenue and marginal cost (risk), rather than simply considering the total cost (risk) or total revenue. Even though the income will increase with the increase of input, the income per unit cost may not be the optimal value at this time.

In each regional logistics integration, the cost, risk, and benefit functions of each individual are different with the different architecture. When the optimal solution of an individual is $h_{i j}{ }^{*} i q_{i j}{ }^{*} \mathrm{i} ; p_{i j}{ }^{*}$, and the optimal state of the supernetwork can be expressed by the optimal solution of all individuals, the equilibrium solution of the supernetwork can be described by a consistent flow, that is the matrix of order $n \times 3 n$, as shown in equation (22).

$$
\begin{aligned}
& {\left[\begin{array}{ccccc}
h_{11}^{*} q_{11}^{*} p_{11}^{*} & h_{12}^{*} q_{12}^{*} p_{12}^{*} & h_{11}^{*} q_{13}^{*} p_{13}^{*} & \ldots & h_{1 k}^{*} q_{1 k}^{*} p_{1 k}^{*} \\
h_{11}^{*} q_{21}^{*} p_{21}^{*} & h_{12}^{*} q_{22}^{*} p_{22}^{*} & h_{13}^{*} q_{23}^{*} p_{23}^{*} & \ldots & h_{1 k}^{*} q_{2 k}^{*} p_{2 k}^{*} \\
h_{11}^{*} q_{31}^{*} p_{31}^{*} & h_{12}^{*} q_{32}^{*} p_{32}^{*} & h_{13}^{*} q_{33}^{*} p_{33}^{*} & \ldots & h_{1 k}^{*} q_{3 k}^{*} p_{3 k}^{*} \\
\ldots & \ldots & \ldots & \ddots & \ldots \\
h_{11}^{*} q_{k 1}^{*} p_{k 1}^{*} & h_{11}^{*} q_{k 2}^{*} p_{k 2}^{*} & h_{11}^{*} q_{k 3}^{*} p_{k 3}^{*} & \ldots & h_{1 k}^{*} q_{k k}^{*} p_{k k}^{*}
\end{array}\right] \text { or }} \\
& {\left[\begin{array}{cccc}
h_{11} h_{12} \ldots h_{1 k} & q_{11} q_{12} \ldots q_{1 k} & p_{11} p_{12} \ldots p_{1 k} \\
h_{21} h_{22} h_{2 k} & q_{21} q_{22} \ldots q_{2 k} & p_{21} p_{22} \ldots p_{2 k} \\
\ldots & \ldots & \ldots \\
h_{k 1} h_{k 2} \ldots h_{k k} & q_{k 1} q_{k 2} \ldots q_{k k} & p_{k 1} p_{k 2} \ldots p_{k k}
\end{array}\right]}
\end{aligned}
$$

When the above equilibrium solution is satisfied, it can be seen that all individuals $i(i=1,2, \ldots, k)$ obtain the maximum benefit. For the logistics system as a whole, the overall interests under the current state are the greatest.

\section{Simulation and Analysis of Supernetwork Equilibrium Model for Regional Logistics Integration}

4.1. Problem Description and Parameter Setting. Assuming that there are three individuals in the process of regional logistics integration, and that the logistics integration is complete with logistics infrastructure and layout network, information and standardization network and organizational relationship level network, the logistics architecture meets the above analysis characteristics. According to the previous analysis, there are 9 nodes in the whole system network. In this chapter, the cost function, profit function and risk function of an individual in the logistics system about the relationship level $h_{i j}$, information flow transmission $q_{i j}$, transportation flow $p_{i j}$, etc., are given. Then, the supernetwork mathematical model of logistics architecture is established and relevant parameters and functions are brought into the model. Finally, the genetic algorithm is used to solve the model, and the maximum value of the objective function in the logistics system and the corresponding parameter levels at this time include relationship level $h_{i j}$, information flow transmission $q_{i j}$, transportation flow $p_{i j}$, etc.

In order to simulate the proposed model, the following assumptions are made:

Hypothesis 1: There are three individuals in the hypernetwork system. These three individuals exist in the logistics infrastructure network, information and standardization network, and organization management network, and have a one-to-one correspondence in the three-tier network.

Hypothesis 2: In the relational network, the relational level is either positive or zero, and the negative relational level is not considered here. The value of transport flow and information flow is also between 0 and 1 , that is $0 \leq h_{i j} \leq 1,0 \leq q_{i j} \leq 1$, $0 \leq p_{i j} \leq 1$.

Hypothesis 3: The individual's income, cost, and risk in the model can be described by the function of corresponding parameters. In practice, the functions of cost and benefit between individual $i$ and different individuals in the system are different, that is, the relationship level $h_{i j}$, information flow transmission $q_{i j}$, and transportation flow $p_{i j}$ have different effects on individual $i$, that is to say, they have different functional relationships. In order to facilitate simulation, this paper assumes that the cost-benefit risk function of individual $i$ is the same as that of other individuals in the same layer network. That is $\xi_{i 1}=\xi_{i 2}=\ldots=\xi_{i j}, \xi=(A, B, C, E, V, U, R)$.

In subsystem networks, an individual can be regarded as a node. $h_{11}, h_{12}, h_{13}$ of an individual 1 represent the relationship level between the node and other nodes in a group operation network, respectively. The benefit of establishing the relationship level is $E_{1 j}=3 * \sin \left((\pi / 2) h_{1 j}\right) \operatorname{cost}$ is $C_{1 j}=\sqrt{h_{1 j}}$, risk is $R_{1 j}=e^{h_{1 j}}$. In Logistics Information and Standardization Network, $q_{11}, q_{12}, q_{13}$ represent information flow between nodes 1 and information and nodes in standardized networks, benefit is $u_{1 j}=2 * \sin \left(3 \pi / 2+\pi q_{1 j}\right)$, cost is $B_{1 j}=2 q_{1 j} /\left(0.1+h_{1 j}\right)+1.5^{q_{1 j}}$. In the logistics facilities and layout network $p_{i j}, p_{11}, p_{12}$, and $p_{13}$ represent the transport flow between nodes 1 and in the 
logistics facilities and layout network, benefit is $V_{1 j}=2.5 p_{1 j}$, cost is $A_{1 j}=2 \sqrt{p_{1 j}}$.

Individual goals are also the five goals of the previous analysis, as shown in Formula (1)-(5). According to the different requirements of the system on the level of relationship value, information benefit, transportation benefit, risk and cost, different weight values can be set to more conform to the actual system. This section of simulation, because the function does not correspond to the meaning of the actual system, in order to facilitate the model does not consider the weight settings. In the practical application of the model, the weight can be set flexibly according to the actual requirements of integration.

4.2. Model Simulation Process. According to the previous hypothesis and model study, the mathematical model of the integrated structure is constructed as shown in formula (23).

$$
\begin{aligned}
\max & 3 \sum_{j=1}^{3}\left(3 * \sin \left(\frac{\pi}{2} h_{i j}\right)-\sqrt{h_{i j}}-e^{h_{i j}}+2 * \sin \left(\frac{3 \pi}{2}+\pi q_{i j}\right)\right. \\
& \left.-\frac{2 q_{i j}}{0.1+h_{i j}}-1.5^{q_{i j}}+2.5 p_{i j}-2 \sqrt{p_{i j}}\right) \\
& \text { st. }\left\{\begin{array}{l}
0 \leq h_{i j} \leq 1, \\
0 \leq q_{i j} \leq 1, \\
0 \leq p_{i j} \leq 1 .
\end{array}\right.
\end{aligned}
$$

The GA genetic algorithm tool in the optimization toolbox of MATLAB is used to simulate and solve the problem. The objective function is used as the adaptive function and the $\mathrm{M}$ file is compiled according to the objective function.

function $y=$ fits $(x)$;

$$
\begin{aligned}
y & =3 *\left(\operatorname{power}(x(1), 2)-\operatorname{power}\left(x(1), \frac{1}{2}\right)\right. \\
& \left.-x(1)+3 * x(2)-\frac{x(2)}{x(1)}+0.2\right)+\exp (x(3)-x(2) * x(3)) ;
\end{aligned}
$$

$y=-y$; population selection using random uniform distribution.

4.3. Analysis of Simulation Results. After 119 iterations, the optimal value of objective function is 8.658 . From the average fitness-optimal fitness of Figures 3 and 4, it can be seen that the model converges quickly, the algorithm has strong technical operability and high efficiency. The results of model simulation show that the best level of relationship level should be 1 , the best level of information flow dissemination should be 1 , and the overall income of individual 1 should be kept at about 1 . The optimal return of individual 1 in the system is 8.658 .

After obtaining the specific numerical results from the model simulation, we can compare the actual value of regional logistics integration with the previous analysis, which can provide some decision-making guidance for system operation and management.

(1) When $h_{i j} \neq h_{i j}{ }^{*}$, it indicates that the construction of relationship level in regional logistics integration is inadequate, and it is necessary to strengthen the construction of relationship level among the main bodies in the organizational operation system. The government and public institutions should play a guiding and regulating role. By formulating relevant policies and providing a good interactive environment, they can really play

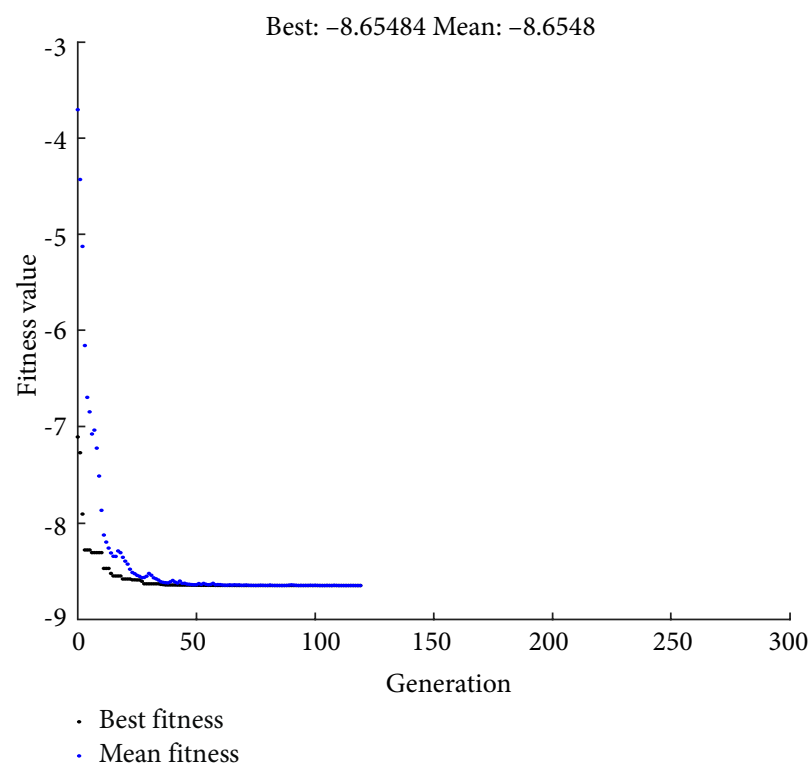

FIgURE 3: Generation and best-mean fitness value.

the role of "invisible hand" and avoid the difficulty of upgrading the level of relations among the main bodies in regional logistics due to the restrictions of external environmental conditions. Industry associations and related service organizations should effectively strengthen the communication and exchange between the government and logistics enterprises, timely discover conflicts between parties, provide relevant services to promote the improvement of the level of the main body relationship in the system, and avoid each logistics body acting independently and self-centered. Logistics enterprises need to examine themselves, actively interact with other enterprises, governments and industry departments, and disseminate knowledge system, improve direct or indirect links with other subjects, and build a level of mutual trust and harmony.

(2) When $q_{i j} \neq q_{i j}{ }^{*}$, it shows that the insufficiency of information and standardization in regional logistics integration restricts the development of logistics system or that the input of information and standardization is too high, and the benefits are not enough to compensate for the cost, and the system is not optimal. To improve the information level of logistics system, enterprises should pay attention to the use of information technology, including effective data collection, processing, excavation, value-added and so on. More importantly, it is important to make rational use of information resources, establish a timely information sharing mechanism among all links and departments, pay attention to the improvement of efficiency and service level brought about by the improvement of information network, actively build information network and seek integration into the industry or, government agencies can play their own advantages, guide the establishment of regional information sharing processing platform for regional objects. Flow provides technical support. As a public sharing platform, its construction process should introduce market resources, carry out market-oriented operation, maximize its resource benefits, and improve the level of logistics information system. In this process, the government can coordinate and tie 


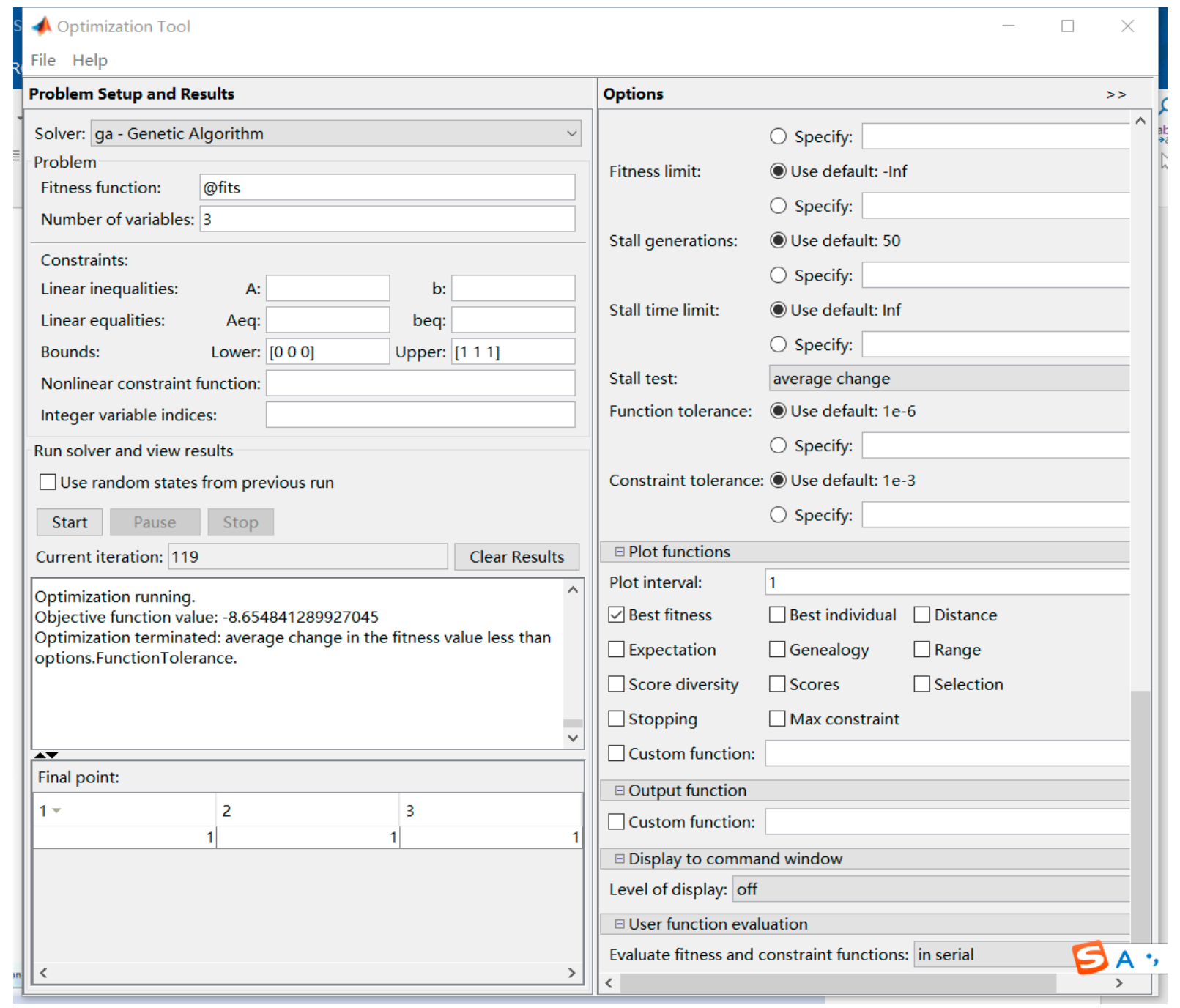

FIGURE 4: Model simulation results.

more lines on the premise of respecting the law of market operation. On the other hand, in the formulation of logistics standardization, government agencies need to play a leading role. In the light of market reality and enterprise needs, they should guide and guide industrial enterprises to formulate a standard system that is conducive to the operation of the system, encourage those industries and enterprises that meet the standards, and guide and correct nonstandards. Through the efforts of all parties, we can reduce the loss caused by insufficient or asymmetric information transmission, and take the information network as the fulcrum to reduce the logistics cost and improve the logistics service level.

(3) When $p_{i j} \neq p_{i j}{ }^{*}$, it means that the network system of facilities and layout in regional logistics integration deviates from the requirement of equilibrium. At this time, we need to focus on the construction of logistics infrastructure, optimize the network layout, including the location of nodes and the lines between them, transport mode selection, etc., to reduce the additional costs caused by unreasonable network.

\section{Conclusion}

The integrated operation of regional logistics has become the future and development direction of regional logistics system construction. At this stage, the research on regional logistics integration has not been deeply studied, especially the principles followed at all levels of regional logistics in its operation process, and the targeted strategies adopted show complexity. Compared with previous studies, hypernetwork method is used to construct a comprehensive logistics structure system model, and the regional logistics system structure mathematical model is further given. At the same time, the weight system is introduced to make it more flexible, more in line with the actual situation, and more practical guidance. It effectively solves the problem that previous studies cannot provide a general mathematical model that can be quantitatively solved and guide the construction and operation of the system, so it is difficult to meet the actual situation of modern logistics system. Meanwhile, the regional logistics system structure model constructed in this paper can be solved and analyzed from two aspects of economy, 
management, and mathematical quantification, providing strong scientific support for specific policy recommendations and other decisions.

Supernetwork equilibrium theory can solve the related problems in the process of regional logistics integration to a certain extent. This paper chooses the level of interlayer relations, the level of information dissemination and the transport flow as decision variables. Under the constraints of marginal cost change and overall revenue, it solves the equilibrium solution of the supernetwork structure operation of regional logistics integration, which makes the process of regional logistics integration possible. The optimal matching and combination of the three decision variables of China-China relationship level, information dissemination level and transport flow can provide reference for the relevant departments and enterprises of regional logistics integration.

\section{Data Availability}

The experimental data used to support the findings of this study are available from the corresponding author upon request.

\section{Conflicts of Interest}

The authors declare that they have no conflicts of interest.

\section{Acknowledgments}

The authors are indebted to anonymous reviewers for their very insightful comments and constructive suggestions, which help ameliorate the quality of this paper. This work was supported in part by Liaoning Provincial Philosophy and Social Science Planning Fund Project (L19BJY037) and National Natural Science Foundation of China (71402104).

\section{References}

[1] N. Ghaffari-Nader, M. Ghazanfari, and E. Teimoury, "Robust optimization approach to the design of hub-and-spoke networks," The International Journal of Advanced Manufacturing Technology, vol. 76, no. 5-8, pp. 1091-1110, 2015.

[2] L. Chong, D. Kennedy, and W. M. Chan, "Direct shipping logistic planning for a hub-and-spoke network with given discrete intershipment times," International Transactions in Operational Research, vol. 13, no. 1, pp. 17-32, 2006.

[3] H. Soleimani and K. Govindan, "Reverse logistics network design and planning utilizing conditional value at risk," European Journal of Operational Research, vol. 237, no. 2, pp. 487-497, 2014.

[4] J. Karkazis and G. C. Baltos, "A risk-based assessment of road networks: country case-study and a wide range of applications covering from logistics operations and security controls to regional geo-economic development," Mediterranean Journal of Social Sciences, vol. 9, no. 6, pp. 9-17, 2018.
[5] D. Zhang, Q. Zhan, Y. Chen, and S. Li, "Joint optimization of logistics infrastructure investments and subsidies in a regional logistics network with $\mathrm{CO}_{2}$ emission reduction targets," Transportation Research Part D: Transport and Environment, vol. 60, pp. 174-190, 2018.

[6] C. Chen, X. Hu, J. Gan, and R. Qiu, "Regional low-carbon timber logistics network design and management using multiobjective optimization," Journal of Forest Research, vol. 22, no. 6, pp. 354-362, 2017.

[7] M. Abbasi and F. Nilsson, "Developing environmentally sustainable logistics: exploring themes and challenges from a logistics service providers' perspective," Transportation Research Part D: Transport and Environment, vol. 46, pp. 273-283, 2016.

[8] D. Zhang, X. Li, Y. Huang, S. Li, and Q. Qian, "A robust optimization model for green regional logistics network design with uncertainty in future logistics demand," Advances in Mechanical Engineering, vol. 7, no. 12, 2015.

[9] S. Wiśniewski, "Significance of trans-European transport networks for logistics centre localization as exemplified by the Łódź region," European Spatial Research and Policy, vol. 22, no. 1, pp. 23-44, 2015.

[10] B. S. Wu and S.J. II, "Study on integrated forecasting technology in logistics demand under supply side reform" Journal of Shenyang University of Technology (Social Science Edition), vol. 10, no. 3, pp. 226-229, 2017.

[11] E. H. S. Abascal and C. A. Bilbao, "Production networks, and digital logistics as a tool for regional development: the wood processing industry in the city of Buri São Paulo," Redes, vol. 15, no. 3, pp. 39-47, 2010.

[12] D. Zhang, S. Li, and J. Qin, "An optimal hierarchical decision model for a regional logistics network with environmental impact consideration," The Scientific World Journal, vol. 2014, Article ID 542548, 15 pages, 2014.

[13] Z. Hu, Y. Zhang, and L. Yao, "Radial basis function neural network with particle swarm optimization algorithms for regional logistics demand prediction," Discrete Dynamics in Nature and Society, vol. 2014, Article ID 414058, 13 pages, 2014.

[14] Y. Liao, R. Hu, and C. Chen, "Informationization, pronduction network externalities and regional logistics," in AASRI Winter International Conference on Engineering and Technology (AASRI-WIET 2013), Atlantic Press, 2013.

[15] N. D. Brunetti, L. De Gennaro, G. Dellegrottaglie, D. Amoruso, G. Antonelli, and M. Di Biase, "A regional prehospital electrocardiogram network with a single telecardiology "Hub" for public emergency medical service: technical requirements, logistics, manpower, and preliminary results," Telemedicine and e-Health, vol. 17, no. 9, pp. 727-733, 2011.

[16] J. Xu, D. Han and D. Liu, "Research on planning of logistics system of equipment manufacturing industry in Liaoning Province," Journal of Shenyang University of Technology (Social Science Edition), vol. 4, no. 3, pp. 201-205, 2011.

[17] Q. Zhang and L. Wei, "Research progress of reverse logistics network design," Management Science in China, vol. 24, no. 9, pp. 165-176, 2016.

[18] T. Li and Z. Wang, "Simulating plant growth algorithms for optimizing the layout of underground logistics network in large cities," System Engineering Theory and Practice, vol. 33, no. 4, pp. 971-980, 2013.

[19] J. Xu and G. Q. Wu, "Research on layout optimization of manufacturing logistics system in new situation," Journal of 
Shenyang University of Technology (Social Science Edition), vol. 11, no. 5, pp. 423-427, 2018.

[20] J. Tang, X. Zhang, and C. Du, "Research on regional logistics network structure based on gravity model-a case study of Jiangsu Province," East China Economic Management, vol. 30, no. 1, pp. 76-82, 2016.

[21] J. Xu, F. J. Yu and Q. Luo, "Research on construction and application of logistics equilibrium theory," Journal of Shenyang University of Technology (Social Science Edition), vol. 8, no. 6, pp. 533-538, 2015. 


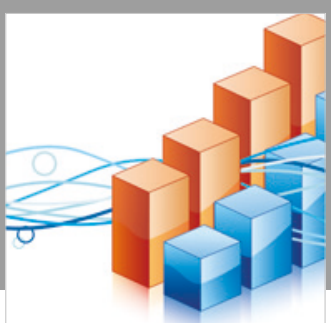

Advances in

Operations Research

\section{-n-m}
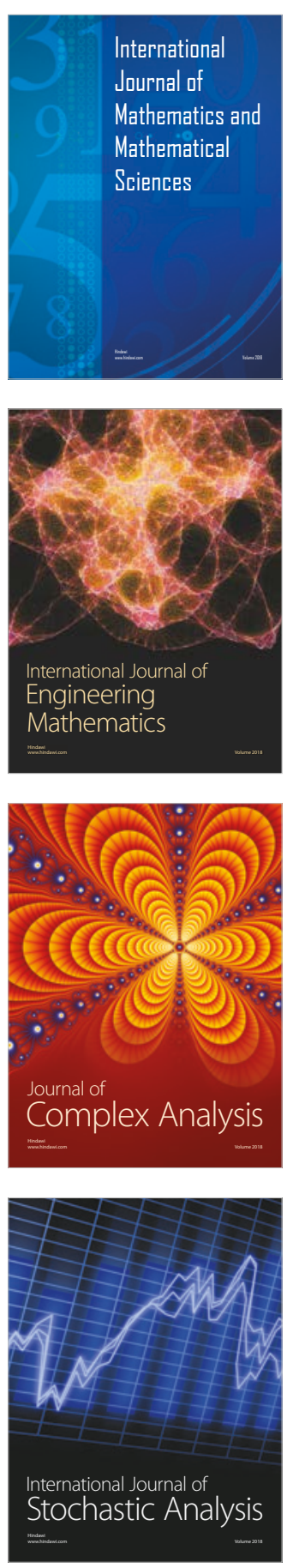
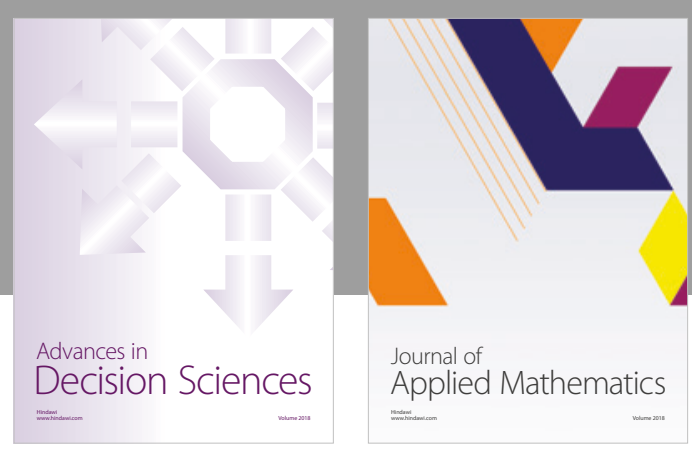

Journal of

Applied Mathematics
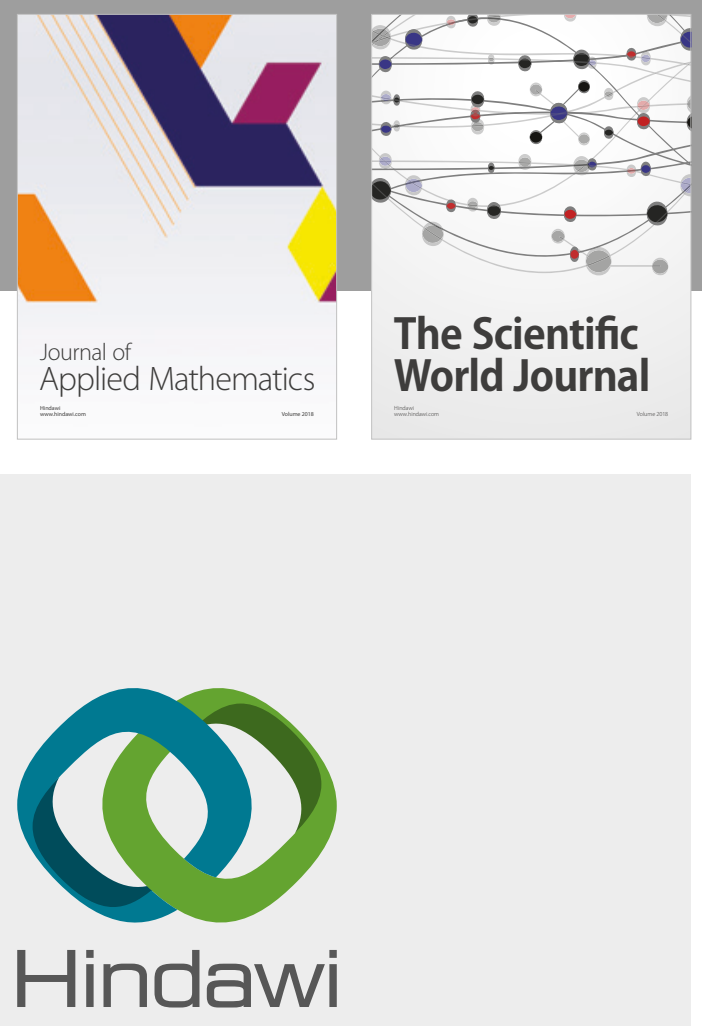

Submit your manuscripts at

www.hindawi.com

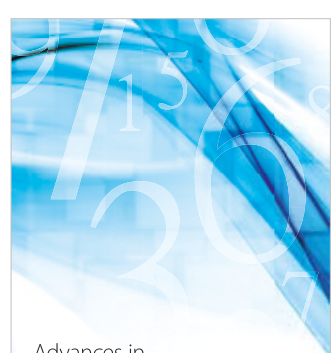

Advances in
Numerical Analysis
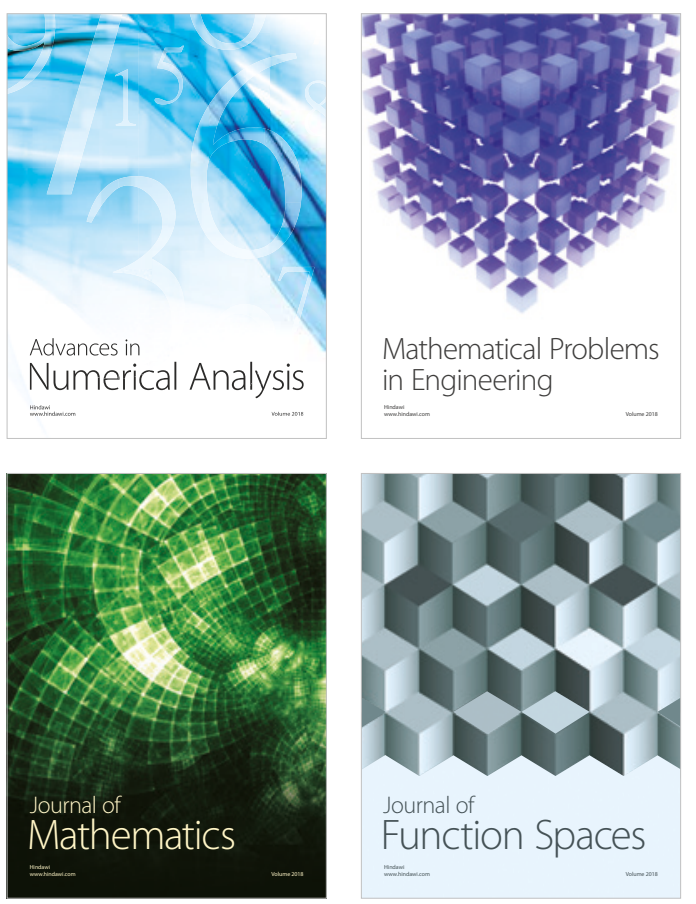

Mathematical Problems in Engineering

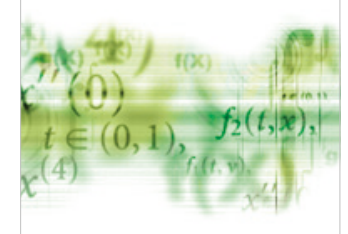

International Journal of

Differential Equations

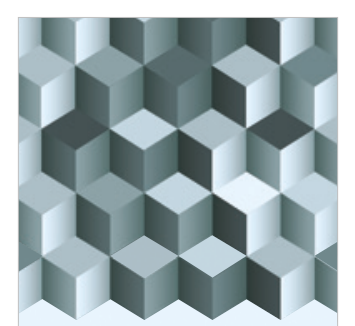

Journal of

Function Spaces
The Scientific

World Journal

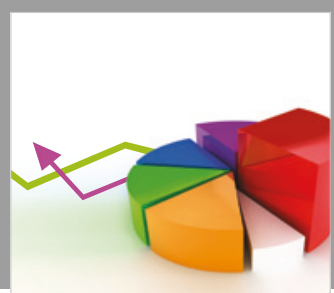

Journal of

Probability and Statistics
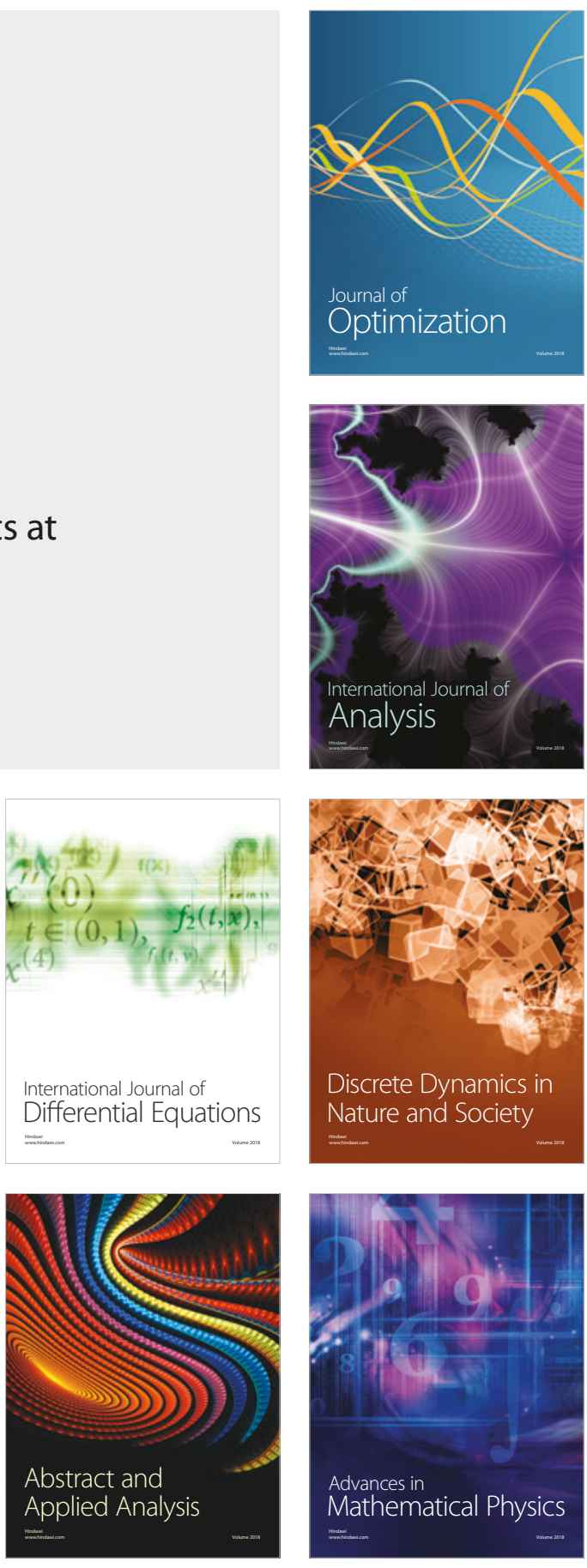